\title{
TI.79.1
}

\section{REN-ISAC Activities and REN-ISAC / Internet2 Focus Group Results}

- PDF: REN-ISAC_20050719_jointtechs.pdf

- Text: REN-ISAC_20050719_jointtechs.txt

\begin{tabular}{|c|c|}
\hline \multicolumn{2}{|c|}{ More Information } \\
\hline Repository ID & TI.79.1 \\
\hline Persistent URL & http://doi.org/10.26869/TI.79.1 \\
\hline Title & REN-ISAC Activities and REN-ISAC / Internet2 Focus Group Results \\
\hline Authors & Doug Pearson \\
\hline Sponsor & SALSA \\
\hline \multicolumn{2}{|l|}{ Review } \\
\hline Status & Legacy \\
\hline Publish Date & July, 2005 \\
\hline DOI & $10.26869 /$ TI.79.1 \\
\hline \multicolumn{2}{|l|}{ Signature } \\
\hline Deprecated & No \\
\hline \multicolumn{2}{|l|}{ Future Review } \\
\hline \multicolumn{2}{|l|}{ Supersedes } \\
\hline Format & PDF, Text \\
\hline \multicolumn{2}{|l|}{ Related Docs } \\
\hline Development Location & middlewarerescue \\
\hline \multicolumn{2}{|l|}{ IP Framework } \\
\hline \multicolumn{2}{|l|}{ Subject Tags } \\
\hline Notes & \\
\hline
\end{tabular}

